\title{
Macular microcirculation in cystoid maculopathy of diabetic patients
}

\author{
Oliver Arend, Andreas Remky, Alon Harris, Bernd Bertram, Martin Reim, Sebastian Wolf
}

\begin{abstract}
Background-In patients with diabetic macular oedema and central cysts ischaemia of the retina appears to be an important contributing factor in the pathogenesis of cysts. This study was performed to further elucidate the role of the inner retinal microcirculation in diabetic cystoid macular oedema (CMO).
\end{abstract}

Methods-Video fluorescein angiography allows visualisation of the macular microvasculature and measurements of the capillary blood velocity (CBV), foveal avascular zone (FAZ), and perifoveal intercapillary area (PIA, characterising capillary density).

Results-Twenty three diabetic subjects with CMO, matched diabetic patients without macular oedema $(n=23)$, and healthy subjects $(n=23)$ were included. CBV, PIA, and FAZ did not differ significantly among diabetic groups regardless of presence of cystoid changes. CBV was significantly reduced $(p<0.0001)$ and PIA was more than doubled in both diabetic groups $(p<0.0001)$ when compared with healthy subjects. Furthermore, FAZ showed a nearly doubled size in diabetic patients without macular oedema $(p<0.01)$ and a less pronounced enlargement (by 29\%) in diabetics with CMO (p<0.05).

Conclusion-The results indicate that the retinal microcirculation in diabetic patients is markedly altered when compared with healthy subjects, regardless of CMO presence. In CMO patients the microcirculatory changes are similar to those of diabetic patients without macular oedema. Thus inner retinal perfusion does not contribute to tissue ischaemia leading to cystoid formations in diabetic maculopathy.

(Brf Ophthalmol 1995; 79: 628-632)

Cystoid macular oedema (CMO) is a nonspecific pathological response to a variety of retinal or choroidal disorders. ${ }^{1-3}$ In diabetic maculopathy cystoid formations are known to occur in association with macular oedema. ${ }^{4}$ The central location of the cysts indicates importance for visual acuity and therefore the understanding of the mechanisms leading to cysts seems noteworthy. ${ }^{4}$

In experimental modelling of diabetic CMO, ischaemic damage of the retinal tissue or photoreceptor/retinal pigment epithelium (RPE) complex appears to be the important contributing factor. ${ }^{5-7}$ Histopathological work ${ }^{7}$ documented minimal damage to the outer photoreceptor segment, indicating that a faulty retinal vasculature appeared causative in the development of $\mathrm{CMO}$, whereas others found only minor retinal alterations. ${ }^{6}$

Videofluorescein angiography provides a detailed visualisation of the foveal capillary network ${ }^{8} 9$ and has proved useful for evaluation of retinal capillary morphology and circulation. ${ }^{10-12}$ In this paper, we describe macular capillary blood velocities, perifoveal intercapillary area (PIA, characterising capillary density), and foveal avascular zone (FAZ) measurements in patients with diabetic macular oedema and central cysts, diabetic patients without macular oedema, and healthy controls. We hypothesised that if retinal ischaemia is the primary driving force in the development of diabetic CMO, then blood velocities should be lowered, in tandem with decreased capillary density and enlarged foveal avascular zone.

\section{Materials and methods}

\section{SUBJECTS}

Twenty three patients with diabetes mellitus and diffuse macular oedema exhibiting a characteristic rosette filling pattern in the fluorescein angiogram $(\mathrm{CMO})^{4}$ were recruited in the current study. In order to compare these patients (a) a diabetic group without clinically significant macular oedema ${ }^{13}$ (match criteria: age, sex, and retinopathy stage); and (b) 23 healthy subjects (matched for age and sex) were included.

All procedures were explained fully to all participants and informed consent was obtained from each subject before the study. Scanning laser ophthalmoscopy (SLO) fluorescein angiographic studies (injection of $10 \%$ sodium fluorescein followed by a flush of $10 \mathrm{ml}$ saline solution) were performed. Normal routine included angiograms of both eyes. For all CMO patients, the eye which was examined first, was selected for study so that leakage and
Augenklinik der

Pauwelsstrasse 30, 52057

Aachen, Germany.

Accepted for publication 26 January 1995 


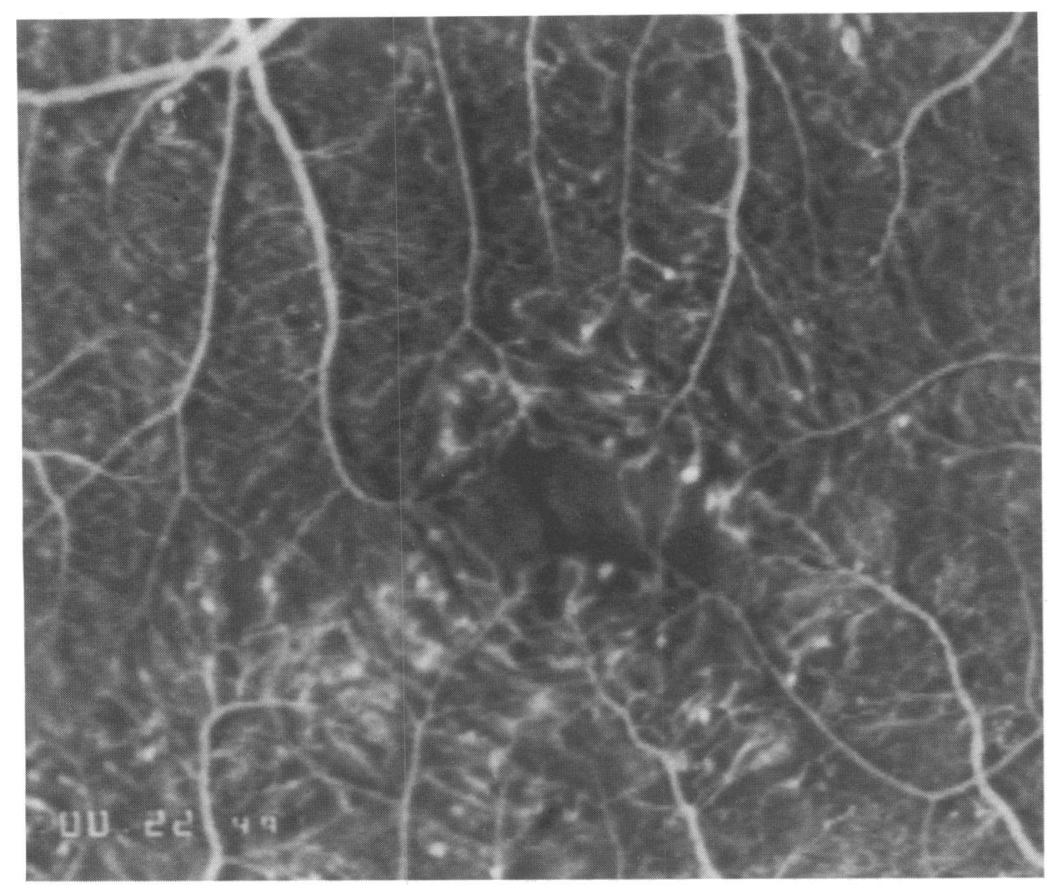

Figure 1 Fluorescein angiogram generated with scanning laser technique of the right eye of a 49-year-old diabetic patient with cystoid macular oedema. The cystoid changes are accompanied by moderate capillary dropout, but excessive parafoveal leakage, which is already visible in this early phase (22 seconds). The foveal avascular zone remains unaffected of occlusions in the surrounding arcade.

masking of fluorescein were minimised. Figures 1-3 illustrate the angiographic findings in two diabetic patients with CMO (Figs 1 and 2) and one without CMO (Fig 3).

Both diabetic patient groups consisted of 17 males and six females: they ranged in age from 26 to 66 years: 52 (SD 11) years CMO patients; 52 (10) years diabetic patients without macular oedema. The mean age in healthy subjects was 50 (12) years, ranging from 29 to 66 (Table 1). Best corrected visual acuity was determined by an ophthalmologist using objective refractometry as well as lighting conditions and standardised charts as described by DIN 58220.14 This was followed by

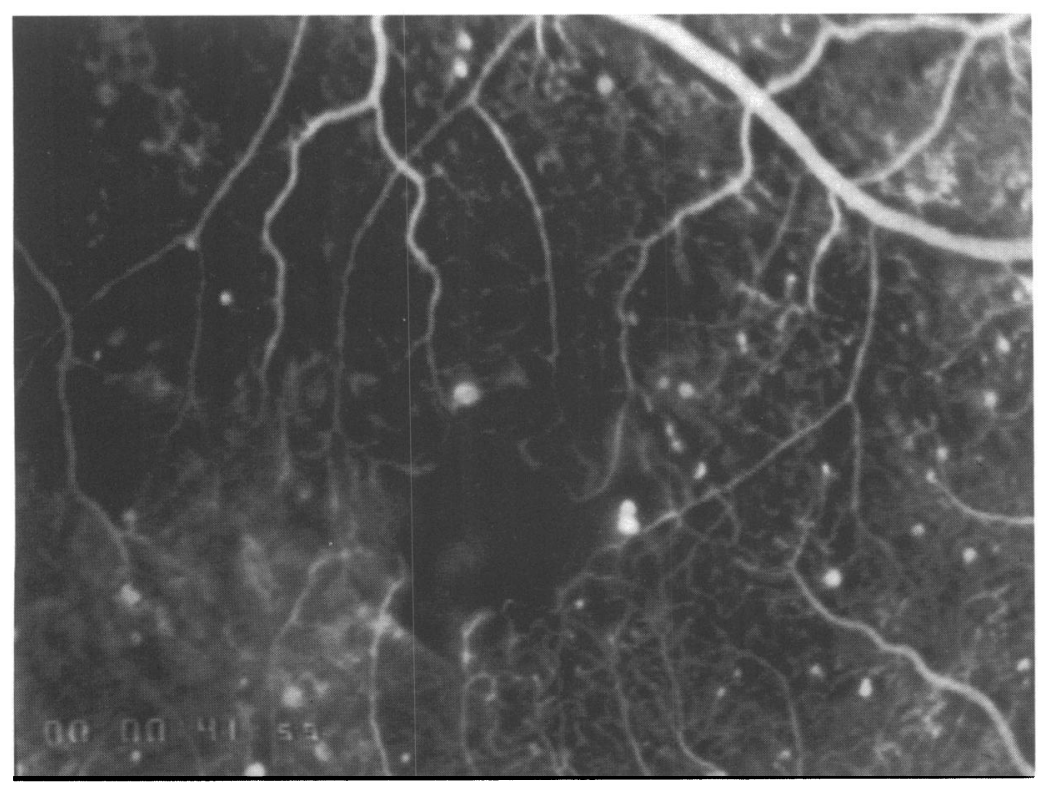

Figure 2 Fluorescein angiogram of the right eye of a 62-year-old, white, male diabetic patient with cystoid macular oedema. The retinal vasculature shows moderate capillary. drop out and the arcade of the foveal avascular zone is only affected by capillary occlusion at the inferior margin. a complete ophthalmic examination. Visual acuity in the CMO group ranged from $6 / 6$ to $6 / 250$ (median visual acuity 6/15) and in the diabetic group without macular oedema from $6 / 9$ to $6 / 5$ (median 6/6). Glucose metabolism was assessed by measuring blood level of haemoglobin $A_{1 c}$ (normal laboratory range $4 \cdot 3-6 \cdot 0 \%$ ). History or evidence of arterial hypertension was present in $11(48 \%)$ of the diabetic patients with CMO and in nine (39\%) of the matched diabetic patients. The diabetic group with CMO consisted of 19 insulin dependent patients (83\%) and four noninsulin dependent $(17 \%)$, and the diabetic patients without macular oedema of $15(65 \%)$ insulin dependent and eight (35\%) non-insulin dependent. Retinopathy level was classified by means of fundus photography according to ETDRS criteria, which scaled diabetic retinopathy into 13 levels ranging from no retinopathy to severe vitreous haemorrhages. ${ }^{15}$ Both diabetic groups were matched for the severity of retinopathy. Stages of diabetic retinopathy included six patients with microaneurysms only or mild non-proliferative diabetic retinopathy (level 20-43), 11 patients with moderate to moderately severe non-proliferative diabetic retinopathy (level 47-53), and six patients with mild to moderate proliferative retinopathy (level 61-65). In none of the patients was a laser treatment (grid or focal) of the posterior pole performed before participation in the study.

\section{METHODS}

The SLO methodology employed in this study has been described in detail elsewhere. ${ }^{10}$ In short, the video signal generated by the scanning laser ophthalmoscope from fluorescein angiograms (20 degree observation field) was digitised and recorded on an image sequence storage unit. In the digital recordings the perifoveal capillary blood velocity (CBV), the area of the FAZ, and the mean PIA were evaluated off line. The mean $\mathrm{CBV}$ was averaged from 100-150 measurements of hypofluorescent gaps in 10 different vessels around the FAZ ( 5 degrees). These velocity measurements were restricted to the capillary formation alone and probably represent rouleaux formations of erythrocytes. ${ }^{16}$ The FAZ was interactively marked and the area calculated from the enclosed pixels. Similarly, PIA was assessed by randomly performing 100 measurements of intercapillary areas around the FAZ and calculating the mean value from these measurements. Thus, PIA represents a capillary density estimate in the perifoveal network. All assessed data were corrected for magnification factor calculated from axial length and keratometry. ${ }^{17} 18$ All data analyses were performed in a masked fashion without knowledge of the patients' clinical examinations.

Mean value and standard deviation are given for all samples with normal distributions (Kolmogorov Smirnov test). Unpaired nonparametric statistical tests (two group analysis: Mann-Whitney U test; multiple group analysis: Kruskal-Wallis test with following sequential 


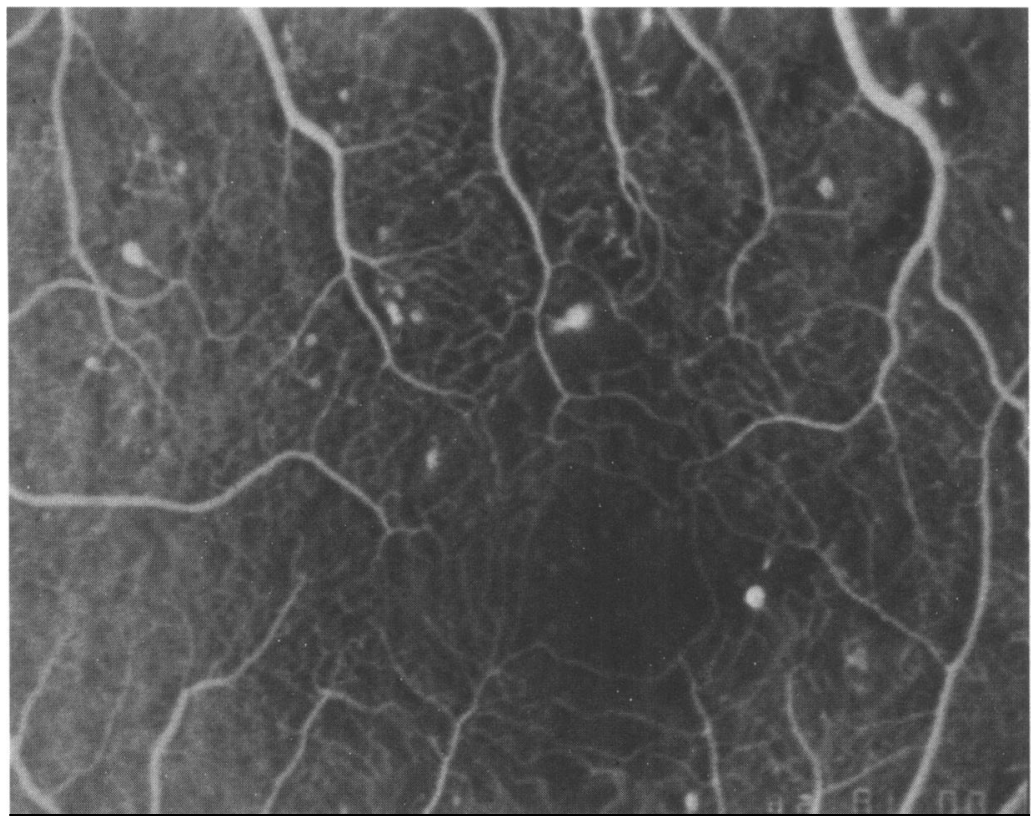

Figure 3 Fluorescein angiogram of the right eye of a 49-year-old diabetic patient without macular oedema. The arcade of the foveal avascular zone remains unaffected, although, the surrounding tissue shows decreased capillary density with large non-perfused areas superior and temporal of the foveal avascular zone.

rejective multiple test procedure ${ }^{19}$ ) were used, as appropriate, to assess the significance of the differences between the groups. Findings with an error probability value smaller or equal to 0.05 were considered to be statistically significant. For statistical analysis all visual acuity scores were converted into numeric equivalents ${ }^{20}$ when calculating median acuity values, or computing correlation coefficients.

\section{Results}

The clinical and demographic data of age and sex did not vary significantly between the three studied groups (Table 1). Evaluation of haemoglobin $A_{1 c}$, the duration of diabetes, diastolic blood pressure and frequency of arterial hypertension, and insulin dependent diabetes mellitus revealed no differences among patients.

Systolic blood pressure $(p<0.01)$ differed significantly among all groups and subgroup analysis showed significant differences of both diabetic groups to healthy subjects, whereas no differences were detected between the diabetic groups. Visual acuity differed significantly $(\mathrm{p}<0.01)$ among the diabetic patient groups, revealing decreased vision in patients with CMO.

The mean CBV differed significantly among all three groups $(p<0 \cdot 0001)$. Subgroup

Table 1 Clinical and demographic data (mean (SD)) of both diabetic groups with CMO and without macular oedema (MO)

\begin{tabular}{|c|c|c|c|c|c|c|}
\hline & \multirow[b]{2}{*}{$\begin{array}{l}\text { No } \\
(M / F)\end{array}$} & \multirow[b]{2}{*}{$\begin{array}{l}\text { Age } \\
\text { (years) }\end{array}$} & \multicolumn{2}{|c|}{ Blood pressure } & \multirow{2}{*}{$\begin{array}{l}\text { Diabetes } \\
\text { duration } \\
\text { (years) }\end{array}$} & \multirow[b]{2}{*}{$\begin{array}{l}H b A_{1 \mathrm{c}} \\
(\%)\end{array}$} \\
\hline & & & $\begin{array}{l}\text { Systolic } \\
(\mathrm{mm} \mathrm{Hg})\end{array}$ & $\begin{array}{l}\text { Diastolic } \\
(\mathrm{mm} \mathrm{Hg})\end{array}$ & & \\
\hline $\begin{array}{l}\text { Diabetic patients (CMO) } \\
\text { Diabetic patients without MO } \\
\text { Healthy subjects } \\
\text { p Value }\end{array}$ & $\begin{array}{l}23(17 / 6) \\
23(17 / 6) \\
23(17 / 6)\end{array}$ & $\begin{array}{l}52(11) \\
52(10) \\
50(12) \\
N^{\star}\end{array}$ & $\begin{array}{l}149(22) \\
145(21) \\
123(8) \\
\mathrm{p}<0.01^{\star}\end{array}$ & $\begin{array}{l}85(14) \\
85(9) \\
77(7) \\
N^{\star}\end{array}$ & $\begin{array}{l}17(7) \\
17(4) \\
- \\
\text { NS† }\end{array}$ & $\begin{array}{l}7 \cdot 2(1 \cdot 4) \\
7 \cdot 4(1 \cdot 4) \\
- \\
\text { NSt }\end{array}$ \\
\hline
\end{tabular}

${ }^{\star}$ Kruskal-Wallis test. $†$ Mann-Whitney $U$ test. NS=not significant. analysis showed no significant differences between CMO patients (CBV $2 \cdot 1(0 \cdot 3) \mathrm{mm} / \mathrm{s}$ ) and matched diabetic patients without macular oedema (CBV $2.3(0 \cdot 2) \mathrm{mm} / \mathrm{s}$ ). Both groups showed significantly reduced CBV $(p<0.0001$; CMO patients $26 \%$; diabetic patients without macular oedema $18 \%$ ) when compared with healthy subjects (CBV $2 \cdot 7(0 \cdot 3) \mathrm{mm} / \mathrm{s}$ ) (Tables 2 and 3 ).

PIA differed significantly between the three studied groups $(p<0.0001)$. In the CMO patient group PIA showed a slight but not significant increase (PIA $10236(2100) \mu \mathrm{m}^{2}$ ) compared with diabetic patients without macular oedema (PIA 9242 (2393) $\mu \mathrm{m}^{2}$ ). Compared with healthy subjects (PIA 3865 (479) $\mu^{2}$ ) PIA was significantly enlarged $(\mathrm{p}<0.0001)$ and more than doubled in both diabetic subgroups (Tables 2 and 3).

Multiple group analysis of FAZ showed significant differences between all studied groups $(p<0 \cdot 01)$. FAZ did not differ significantly among the CMO population (FAZ $\left.0.311(0.13) \mathrm{mm}^{2}\right)$ and diabetic patients without macular oedema (FAZ $\left.0.411(0 \cdot 22) \mathrm{mm}^{2}\right)$. When compared with healthy subjects (FAZ $\left.0.221(0.09) \mathrm{mm}^{2}\right)$, FAZ was significantly $(p<0.05,29 \%)$ enlarged in patients with CMO and nearly doubled in diabetic patients without macular oedema $(p<0.01)$ (Tables 2 and 3$)$.

\section{Discussion}

A variety of diseases can be associated with CMO. ${ }^{1}$ In diabetic patients only a subset of patients with diabetic macular oedema show central cysts $(7 \%),{ }^{21}$ however, because of the potentially serious effects on visual acuity the understanding of the pathogenic mechanisms is crucial.

Histopathological work ${ }^{7}$ has identified a widespread swelling and degeneration of the Mueller's cell cytoplasm. However, the mechanism leading to oedema of the Mueller cell is not clear. Experimental modelling provided four causative factors, which could induce CMO. ${ }^{62}$ In diabetic patients (two of them) microinfarcts in the outer plexiform and inner nuclear layers, and/or leakage of the RPE could result in CMO ${ }^{67}$ In both models, ischaemia resulting either from incompetent retinal vasculature or retinal pigment epithelium is thought to play a major role in the pathogenesis of the cystoid formation. 5622

Fluorescein angiography provides an extremely useful clinical tool for studies elucidating clinical findings of CMO. ${ }^{2}{ }^{323-25}$ Using video fluorescein angiography generated with scanning laser technology in diabetic patients, we were able to visualise macular morphology and circulation. ${ }^{10-12}$

In this study, macular CBV in diabetic patients with CMO and without macular oedema was significantly decreased compared with healthy subjects. Among the diabetic patient groups, no significant differences were measured. The uniform velocity reduction measured in diabetic patients, regardless of absence or presence of CMO, could be the result of various factors including altered blood 
Table 2 Capillary blood velocity (CBV), perifoveal intercapillary area (PLA), and foveal avascular zone (FAZ) in the diabetic patients with CMO and without macular oedema (MO) and healthy subjects (mean (SD))

\begin{tabular}{|c|c|c|c|c|}
\hline & No & $\begin{array}{l}C B V \\
(\mathrm{~mm} / \mathrm{s})\end{array}$ & $\begin{array}{l}P I A \\
\left(\mu m^{2}\right)\end{array}$ & $\begin{array}{l}F A Z \\
\left(m m^{2}\right)\end{array}$ \\
\hline $\begin{array}{l}\text { Diabetic patients (CMO) } \\
\text { Diabetic patients without MO } \\
\text { Healthy subjects } \\
\text { p Value }\end{array}$ & $\begin{array}{l}23 \\
23 \\
23\end{array}$ & $\begin{array}{l}2 \cdot 13(0 \cdot 29) \\
2 \cdot 28(0 \cdot 24) \\
2 \cdot 69(0 \cdot 26) \\
\mathrm{p}<0.0001\end{array}$ & $\begin{array}{l}10236(2101) \\
9243(2393) \\
3865(479) \\
\mathrm{p}<0.0001\end{array}$ & $\begin{array}{l}0.311(0.13) \\
0.411(0.22) \\
0.221(0.09) \\
\mathrm{p}<0.01\end{array}$ \\
\hline
\end{tabular}

^Kruskal-Wallis test.

fluidity, ${ }^{2627}$ pathologic leucocyte interactions, ${ }^{28}$ capillary occlusions, ${ }^{29}$ or vessel wall affections. $^{30}$ Another interpretation of the reduced velocities in CMO is that once the cystoid formation developed, the cysts themselves could cause increased tissue pressures, which could lead to capillary collapse and therefore reduced capillary perfusion. ${ }^{31}$ In our study, there was a trend towards further decrease $(7 \%)$ of CBV in patients with CMO. However, it is difficult to judge the importance of these influences and whether the investigated changes in patients with $\mathrm{CMO}$ are the result of the cystoid formation or other vascular diabetic changes.

With decreased capillary perfusion, morphology analysis of the retinal microvasculature is an important factor in the understanding of the microvasculatory status of the tissue. In the present study, PIA and FAZ in diabetic patients with CMO did not differ significantly from those without macular oedema although in those without macular oedema the FAZ changes were more pronounced. The comparison with healthy subjects showed that the FAZ was almost doubled in the diabetic patients without macular oedema and enlarged by $29 \%$ in CMO patients. PIA was more than doubled in both diabetic groups. Smith et al ${ }^{32}$ presented morphological data from diabetic patients with macular oedema, which revealed that the FAZ grading was independent of retinal thickening and the breakdown of the blood-retinal barrier. Previous works demonstrated progressive capillary loss in the perifoveal network of diabetic patients ${ }^{10-12}$ in tandem with enlarging FAZ and increased retinopathy level, ${ }^{11} 123334$ which suggests that chronic ischaemia could be the underlying vascular pathological factor resulting in the progression of the disease. Interestingly, in

Table 3 Statistical differences of the capillary blood velocity $(C B V)$, perifoveal intercapillary area (PIA), and foveal avascular zone (FAZ) between healthy subjects, diabetic patients with CMO, and without macular oedema (MO)

\begin{tabular}{llll}
\hline & $H S$ & CMO & Without NO \\
\hline CBV: & & & \\
HS & - & $\mathrm{p}<0.0001$ & $\mathrm{p}<0.0001$ \\
CMO & - & - & $\mathrm{NS}$ \\
Without MO & - & - & - \\
PIA: & - & $\mathrm{p}<0.0001$ & $\mathrm{p}<0.0001$ \\
HS & - & - & $\mathrm{NS}$ \\
CMO & - & - & - \\
Without MO & - & $\mathrm{p}=0.03$ & $\mathrm{p}=0.002$ \\
FAZ: & - & - & NS \\
HS & - & - & - \\
CMO & & & \\
Without MO & &
\end{tabular}

$\mathrm{HS}=$ healthy subjects; $\mathrm{CMO}=$ diabetic patients with $\mathrm{CMO}$; Without $M O=$ diabetic population without macular oedema. diabetic patients with CMO, no further CBV reduction or PIA and FAZ enlargements could be detected leading to an ischaemic stimulus of the retinal vasculature and the development of CMO.

In summary, the scanning laser technique allowed us to more clearly elucidate the role of ischaemia in patients with CMO than it was possible before. The study revealed that macular CBV was significantly reduced and the FAZ, in tandem with PIA, significantly enlarged (decreased capillary density) compared with healthy subjects. Furthermore, no significant differences could be documented between the two diabetes groups for CBV, PIA, and FAZ, regardless of whether CMO was present or not. These results suggest that inner retinal ischaemia does not contribute to tissue ischaemia leading to cystoid formations in diabetes mellitus.

This investigation was supported by the Deutsche Research to Prevent Blindness (IU) and NIH Grant EY 10801Resear.

1 Yanoff M, Fine BS, Brucker AJ, Eagle RCJ. Pathology of human cystoid macular edema. Surv Ophthalmol 1984; 28 (suppl): 505-11

2 Gass JDM, Norton EWD. Cystoid macular edema and papilledema following cataract extraction. Arch Ophthalmol 1966; 76: 646-61.

3 Coscas G, Gaudric A. Natural course of nonphakic cystoid macular edema. Surv Ophthalmol 1984; 28 (suppl): 471-84.

4 Bresnick GH. Diabetic macular edema. A review. Ophthalmology 1986; 93: 989-97.

5 Bellhorn RW. Analysis of animal models of macular edema. Surv Ophthalmol 1984; 28 (suppl): 520-4.

6 Tso MOM. Animal modelling of cystoid macular edema Surv Ophthalmol 1984; 28 (suppl): 512-9.

7 Fine BS, Brucker AJ. Macular edema and cystoid macular edema. Am $\mathcal{F}$ Ophthalmol 1981; 92: 466-81.

8 Wolf S, Toonen H, Arend O, Jung F, Kaupp A, Kiesewetter, et al. Zur Quantifizierung der retinalen Kapillardurchblutung mit Hilfe des Scanning-LaserOphthalmoskops. Biomed Tech 1990; 35: 131-4.

9 Nasemann JE, Müller M. Scanning laser angiography. In: Naseman JE, Burk ROW, eds. Scanning laser ophthalmoscopy and tomography. Munich: Quintessenz Verlag 1990: 63-80.

10 Wolf S, Arend O, Toonen H, Bertram B, Jung F, Reim M. Retinal capillary blood flow measurement with a scanning laser ophthalmoscope. Preliminary results. Ophthalmology 1991; 98: 996-1000.

11 Arend O, Wolf S, Jung F, Bertram B, Pöstgens H, Toonen $\mathrm{H}$, et al. Retinal microcirculation in patients with diabetes mellitus: dynamic and morphologic analysis of perifoveal capillary network. Br ₹ Ophthalmol 1991; 75: 514-8.

12 Arend O, Wolf S, Remky A, Sponsel WE, Harris A, Bertram $\mathrm{B}$, et al. Perifoveal microcirculation with non-insulin dependent diabetes mellitus. Graefes Arch Clin Exp Ophthalmol 1994; 232: 225-31.

13 Early Treatment Diabetic Retinopathy Study Research Group. Photocoagulation for diabetic macular edema. Early Treatment Diabetic Retinopathy Study Repor Number 1. Arch Ophthalmol 1985; 103: 1796-806.

14 Normenausschuss Feinmechanik und Optik. DIN 58220 (1974-1990), B1.3 (1974) Sehschärfenbestimmung, Teil 1 (1988) Normsehzeichen, Teil 2 (1989) Anschluss von Sehzeichen, Teil 3 (1990) Prüfung für Gutachten, Teil 4 (1980) Nahvisusbestimmung, Teil 5 (1986) Allgemeine Sehtestung, Teil 6 (1988) Strassenverkehrsbezogener Sehtest. In: B Dtsch Institut für Normung e V Beuth ed. 1990.

15 Early Treatment Diabetic Retinopathy Study Research Group. Fundus photographic risk factors for progression of diabetic retinopathy. ETDRS Report Number 12 Ophthalmology 1991; 98 (suppl): 823-33.

16 Arend O, Harris A, Wolf S. Capillary blood flow velocity measurements in cystoid macular edema with the scanning laser ophthalmoscope. Am f Ophthalmol 1994 117: 819-20.

17 Bennett AG, Rudnicka AR, Edgar DF. Improvements on Littmann's method of determining the size of retinal features by fundus photography. Graefes Arch Clin Exp Ophthalmol 1994; 232: 361-7.

18 Littmann H. Zur Bestimmung der wahren Grösse eines Objektes auf dem Hintergrund eines lebenden Auges. Klin Monatsbl Augenheilkd 1988; 192: 66-7.

19 Holm S. A simple sequentially rejective multiple test procedure. Scand F Statist 1979; 6: 65-70.

20 Hartmann E. Ophthalmologische Optik-Sehschärfebestimmung. Klin Monatsbl Augenheilkd 1987; 191: 62-8. 
21 Klein $R$, Klein BEK, Moss SE. Visual impairment in diabetes. Ophthalmology 1984; 91: 1464-74.

22 Tso MOM. Pathology of cystoid macular edema. Ophthalmology 1982; 89: 902-15.

23 Schatz H, Patz A. Cystoid maculopathy in diabetics. Arch Ophthalmol 1976; 94: 761-8.

24 Gass JDM, Anderson DR, Davis EB. A clinical, fluorescein angiographic, and electron microscopic correlation of cystoid macular edema. Am f Ophthalmol 1985; 100: 82-6.

25 Ohnishi Y, Fujisawa K, Ishibashi T, Kojima H. Capillary blood flow velocity measurements in cystoid macular edema with the scanning laser ophthalmoscope. Am $\mathfrak{f}$ Ophthalmol 1994; 117: 24-9.

26 McMillan DE. The blood viscosity problem in diabetes. Clin Diabetes 1989; 7: 61, 66-9, 71 .

27 Bertram B, Wolf S, Arend O, Schulte K, Pesch TW, Jung F, et al. Blood rheology and retinopathy in adult type diabetes mellitus. Clin Hemorheol 1992; 12: 437-48.

28 Schröder S, Palinski W, Schmid-Schönbein GW. Activated monocytes and granulocytes, capillary nonperfusion, and neovascularization in diabetic retinopathy. Am $\mathcal{F}$ Pathol 1991; 139: 81-100

29 Ashton N. Studies of the retinal capillaries in relation to diabetic and other retinopathies. Br $\mathcal{F}$ Ophthalmol 1963; 47: 521-38.

30 Ashton N. Vascular basement membrane changes in diabetic retinopathy, $\mathrm{Br} \mathcal{f}$ Ophthalmol 1974; 58 344-66.

31 Hamilton AM, Kohner EM, Rosen D, Bird AC, Dollery CT. Experimental retinal branch vein occlusion in rhesus monkeys. I. Clinical appearances. Br $\mathcal{f}$ Ophthalmol 1979; 63: $377-87$.

32 Smith RT, Lee CM, Charles HC, Farber M, Cunha-Vaz JG. Quantification of diabetic macular edema. Arch

33 Bresnick GH, Condit R, Syriala S, Palta M, Groo A, Korth $K$. Abnormalities of the foveal avascular zone in diabetic retinopathy. Arch Ophthalmol 1984; 102: 1286-93.

34 Mansour AM, Schachat A, Bodiford G, Haymond R. Foveal avascular zone in diabetes mellitus. Retina 1993; 13: $125-8$. 